
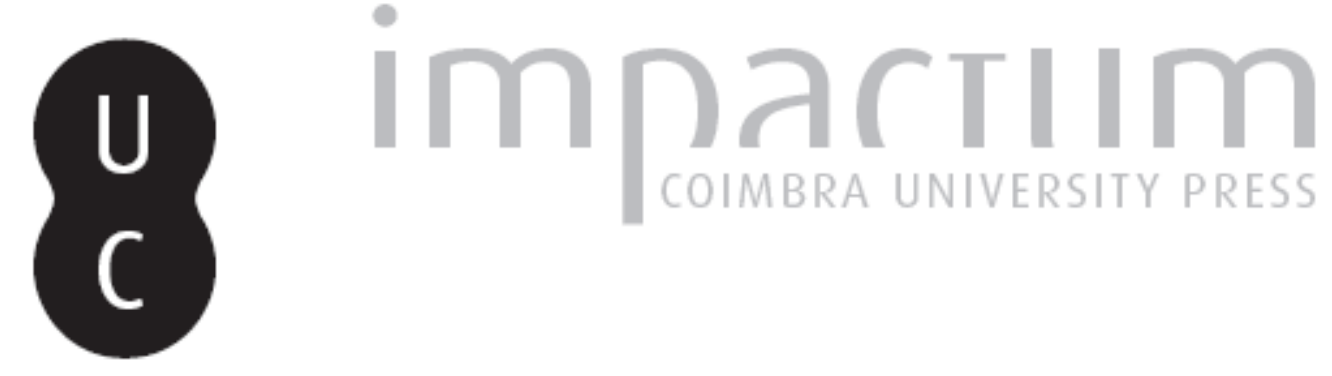

\title{
A cobertura da morte de figuras públicas na imprensa portuguesa: contributos para uma categorização das personagens mediáticas
}

Autor(es): Mota, Joana Margarida Martins

Publicado por: Imprensa da Universidade de Coimbra

URL persistente:

URI:http://hdl.handle.net/10316.2/43608

DOI:

DOl:https://doi.org/10.14195/2183-6019_6_5

Accessed : $\quad$ 26-Apr-2023 15:32:38

A navegação consulta e descarregamento dos títulos inseridos nas Bibliotecas Digitais UC Digitalis, UC Pombalina e UC Impactum, pressupõem a aceitação plena e sem reservas dos Termos e Condições de Uso destas Bibliotecas Digitais, disponíveis em https://digitalis.uc.pt/pt-pt/termos.

Conforme exposto nos referidos Termos e Condições de Uso, o descarregamento de títulos de acesso restrito requer uma licença válida de autorização devendo o utilizador aceder ao(s) documento(s) a partir de um endereço de IP da instituição detentora da supramencionada licença.

Ao utilizador é apenas permitido o descarregamento para uso pessoal, pelo que o emprego do(s) título(s) descarregado(s) para outro fim, designadamente comercial, carece de autorização do respetivo autor ou editor da obra.

Na medida em que todas as obras da UC Digitalis se encontram protegidas pelo Código do Direito de Autor e Direitos Conexos e demais legislação aplicável, toda a cópia, parcial ou total, deste documento, nos casos em que é legalmente admitida, deverá conter ou fazer-se acompanhar por este aviso.

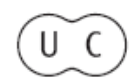


revista de comunicação,

jornalismo e espaço público

\section{6}

Periodicidade

Semestral

Imprensa da Universidade de Coimbra

Coimbra University Press

\section{mediapolis}

personagens mediáticas:

teoria, problemas, análises media characters:

theory, problems, analyses 


\section{A cobertura da morte de figuras públicas na imprensa portuguesa.}

\section{Contributos para uma categorização das personagens mediáticas}

The death of public figures in the Portuguese press. Contributions to a categorization of media characters

\section{Resumo}

A morte de figuras públicas assume relevância para os media, dada a presença dos valores-notícia da morte e da notoriedade. No entanto, não basta que se verifiquem estes critérios, para que estejamos perante um grau de noticiabilidade estanque.

A partir do estudo da morte de 20 figuras públicas, chegámos a diferentes tratamentos por parte dos três jornais diários selecionados - o Correio da Manhã, o Diário de Notícias e Jornal de Notícias. Concluímos, pois, que a maior ou menor noticiabilidade se prende, quer com o estatuto da personalidade, quer com o posicionamento editorial do meio de comunicação social e ainda com algumas contingências do período em que ocorre o acontecimento. Assim, propomos a categorização das figuras públicas, cuja morte foi alvo de cobertura mediática, com base no estudo dos diferentes estatutos de personalidades, como heróis, mitos, celebridades, estrelas e fama, alguns dos quais diretamente dependentes dos media e, outros, oriundos dos estudos narrativos.

Palavras-chave: morte, figuras públicas, celebridades, narrativas mediáticas.

\section{Abstract}

The death of public figures assumes relevance to the media, given the presence of the news-values of death and notoriety. However, it is not enough to identify these two criteria, because the newsworthiness it's not pond.

From the study of the death of 20 public figures, we noticed the different treatments from the three daily newspapers selected Correio da Manhã, Diário de Notícias and Jornal de Notícias. We concluded, therefore, that the greater or lesser newsworthiness arises, either with the status of the personality, or with the editorial position of the media, and with some contingencies of the period in which the event occurs.

Thus, we propose the categorization of public figures, whose death was covered by the media, based on the study of the different statutes of personalities, such as heroes, myths, celebrities, stars and fame, some of them directly dependent on the media and, of narrative studies.

Keywords: death, public figures, celebrities, media narratives 
Os meios de comunicação social assumem a morte como um dos critérios de noticiabilidade e, nesse sentido, fazem dela notícia sempre que a proximidade ou notoriedade da pessoa envolvida, o inesperado da ocorrência ou a negatividade do caso adquirem força suficiente para se transformar em valores-notícia.

Foi intenção da nossa investigação explorar o tratamento noticioso dado à morte de duas dezenas de figuras públicas, num período temporal superior a 40 anos, em três jornais diários portugueses. A narrativa mediática da morte de António de Oliveira Salazar, Fernando Pascoal das Neves, Francisco Sá Carneiro, Joaquim Agostinho, António Variações, José Afonso, Carlos Paião, Miguel Torga, Beatriz Costa, António de Spínola, Vítor Baptista, Amália Rodrigues, Sophia de Mello Breyner, Álvaro Cunhal, José Megre, Raul Solnado, José Saramago, António Feio, Angélico Vieira e Eusébio da Silva Ferreira foi analisada a partir das edições do Correio da Manhã, Diário de Notícias e Jornal de Notícias. Encontrámos tratamentos similares em alguns casos e coberturas diferenciadas em outros, consoante o perfil de cada periódico e mediante o grau de notoriedade da personalidade em causa. Concomitantemente, percebemos que a cobertura da morte de cada uma das figuras selecionadas para este estudo resultou de diferentes estatutos de visibilidade, que podem ajudar a compreender a perspetiva que os media têm daquela personalidade pública.

\section{As categorias}

Procurámos analisar os vários tipos de personalidades com destaque na vida pública, olhando-os através de diferentes conceitos: heróis, mitos, celebridades, estrelas e fama.

Entendemos como celebridade uma personalidade que recebe atenção dos media, em graus variáveis consoante o estatuto alcançado (um ator pode ser mais ou menos famoso, consoante faça papéis com mais ou menos destaque, na televisão ou no teatro, sendo que a primeira tem mais visibilidade do que o segundo) e que atinge uma notoriedade pública que pode ser mais ou menos fugaz (Hartley, 2004) e que pode ser diferenciada mediante o status da personalidade (Rojek, 2001). A categoria da celebridade está diretamente dependente da exposição mediática nos meios de comunicação social de massas, tal como defendem vários autores (Boorstin, 2006; Cashmore, 2006; Marshall, 2006) e de uma narrativa ou história de vida que mereça o interesse destes meios (Gabler, 2001). Assim, falar de celebridade é falar de uma personalidade que publicita os seus feitos através dos media de massas (Turner, 2004), estando por isso inserida na sociedade do espetáculo (Cintra Torres, 2011) e podendo, aliás, ser criada pelos próprios media. Tal como defende Turner (2004), o feito mais importante da celebridade é a capacidade de atrair o público para a sua história de vida, a qual assume mais importância do que a vertente profissional, sendo que a celebridade não necessita de ter nenhum talento em concreto para ser considerada como tal (Cashmore, 2006).

Quanto ao conceito de estrela, esta é considerada "produto de um meio em particular", como por exemplo a indústria de Hollywood (Hartley, 2004) ou do star system brasileiro (Coelho, 2011). Para autores como Campbell (1990), o cinema cria as estrelas e a televisão cria as celebridades, sendo 
as primeiras mais duradouras do que as segundas. Está aqui subjacente uma ideia de grandiosidade da personalidade para que seja considerada uma estrela, bem como uma posição mais duradoura no panorama mediático.

Para Gabler (2001) a fama é uma condição adquirida pela sobre-exposição aos media. Assim, o conceito de fama, patente na categoria do Famoso, descreve uma personalidade conhecida publicamente pelos seus atos, que não usufrui, necessariamente, de um grau de atenção contínuo por parte dos meios de comunicação de massas. Prende-se com a condição de alguém glorificado mediante a sua ação em determinada área de atuação (Rockwell e Giles, 2009). O famoso, ao contrário da celebridade, não necessita de uma narrativa pessoal interessante, nem para o público, nem para os meios de comunicação social (Gabler, 2001).

Já o Herói pode ser descrito como uma personalidade humana, real ou imaginada, que alcança um determinado feito reconhecido como grandioso do ponto de vista coletivo (Boorstin, 2006; Reis, 2015). É, por isso, uma autocriação no sentido em que os
Assim, o conceito de fama, patente na categoria do Famoso, descreve uma personalidade conhecida

publicamente

pelos seus atos, que não usufrui, necessariamente, de um grau

de atenção

contínuo por

parte dos meios

de comunicação

de massas. seus feitos o distinguem dos restantes homens (Campbell, 1994) e diferenciando-se assim da celebridade, que pode ser fabricada (Boorstin, 2006). $\mathrm{O}$ conceito de herói emerge de uma ação, fruto da superação de um desafio, e de habilidades especiais com impacto e reconhecimento na sociedade. Apesar da sua maior ou menor mediatização, necessária para os seus atos se tornarem públicos, o herói desfruta, relativamente à celebridade, de uma maior autonomia que deriva dos feitos que realiza ou é capaz de realizar. O herói é uma criação de si mesmo, enquanto a celebridade é uma criação dos meios de comunicação social (Boorstin, 2006).

$\mathrm{O}$ conceito de Mito pode ser definido como a personalidade que se assume como modelo para a vida de outros (Campbell, 1990). Trata-se de uma imagem construída de uma figura real ou personagem sobrenatural, muitas vezes envolta numa aura de misticismo, cujo estatuto está diretamente relacionado com a tradição oral que prolonga esse estatuto no tempo, o que permite o acrescento de detalhes do domínio do irreal e da imaginação (Parafita, 2012). 
Por sua vez, a Vedeta é a personalidade que ambiciona tornar-se uma estrela, mas não o é. Distingue-se da celebridade porque está inserida no mesmo star-system das estrelas, mas ainda não alcançou esse estatuto e a sua fama é de curta duração (Santos, 2011). As vedetas são vistas como estrelas mais convencionais, na medida em que precisam de alimentar a sua narrativa central para obter a atenção dos media e quando essa narrativa se esbate elas são transformadas em celebridades menores.

\section{A categorização aplicada} às narrativas mediáticas da morte das figuras públicas

O estudo da morte de António de Oliveira Salazar, Fernando Pascoal das Neves, Francisco Sá Carneiro, Joaquim Agostinho, António Variações, José Afonso, Carlos Paião, Miguel Torga, Beatriz Costa, António de Spínola, Vítor Baptista, Amália Rodrigues, Sophia de Mello Breyner, Álvaro Cunhal, José Megre, Raul Solnado, José Saramago, António Feio, Angélico Vieira e Eusébio da Silva Ferreira foi realizado a partir das edições do Correio da Manhã, Diário de Notícias e Jornal de Notícias. Foram contabilizadas as onze edições após a morte, as efemérides de um mês, seis meses, um ano, e, nos casos em que foi possível 10 , 20 e 30 anos. Os dados recolhidos deixaram-nos vários traços de uma possível metodologia de caracterização do estatuto de figuras públicas pelos media, tendo por referência as definições e as tipologias propostas por vários autores.

A proposta que fazemos parte de dois pressupostos: 1) que estamos a falar de uma realidade contemporânea que parte de uma narrativa mediática; 2) que estas conclusões não podem ser pensadas fora de quadros discursivos mais gerais (a história, a ficção, a política, etc.) igualmente determinantes. Deste modo, a categorização que propomos é a expressão de construções narrativas publicitadas nos media, e de que os media são, simultaneamente, produto e produtores. Como tal, não pretendemos aqui estabelecer uma tipologia estanque, nem tão pouco pretendemos impor qualquer regra, visto que a categorização aqui proposta resulta da análise da cobertura mediática da morte das 20 personalidades espácio-temporalmente definidas, não podendo nós considerar o discurso social como cristalizado e definitivo.

Ainda que as circunstâncias da morte tenham uma influência direta na produção de conteúdos informativos, a maior ou menor noticiabilidade da morte de uma figura pública não é independente da notoriedade adquirida durante a sua vida, pelo que existe um certo grau de autonomia de que gozam algumas das personalidades, em relação aos meios de comunicação social.

Optámos por construir um quadro de análise, baseado nos dados retirados da cobertura realizada pelos jornais, com o objetivo de os cruzar com as categorias das personalidades públicas. Incluímos nesta tabela o número de páginas onde a personalidade foi referenciada, o número de peças, o número de imagens, o número de destaques de capa, o número de efemérides assinaladas e o número total de artigos, crónicas e editoriais, este último ponto visando aferir o peso da opinião. 
Tabela 1 - Total de destaques

das personalidades

\begin{tabular}{|c|c|c|c|c|c|c|c|c|}
\hline Personalidade & Páginas & Peças & Imagens & Dest. Capa & Efemérides & Opinião & SOMA & Posição \\
\hline Álvaro Cunhal & 175 & 193 & 259 & 10 & 3 & 53 & 693 & 3 \\
\hline Amália Rodrigues & 119 & 196 & 206 & 13 & 8 & 38 & 567 & 5 \\
\hline Angélico Vieira & 52 & 92 & 177 & 10 & 1 & 2 & 334 & 7 \\
\hline António de Spínola & 24 & 36 & 38 & 4 & 1 & 12 & 115 & 13 \\
\hline António Feio & 23 & 48 & 81 & 5 & 1 & 3 & 161 & 11 \\
\hline António Variações & 16 & 14 & 10 & 4 & 3 & 1 & 48 & 17 \\
\hline Beatriz Costa & 18 & 22 & 29 & 3 & 0 & 5 & 77 & 16 \\
\hline Carlos Paião & 9 & 7 & 9 & 3 & 1 & 0 & 29 & 18 \\
\hline Eusébio & 202 & 420 & 446 & 17 & 3 & 79 & 1161 & 1 \\
\hline Joaquim Agostinho & 41 & 65 & 74 & 7 & 7 & 4 & 198 & 9 \\
\hline José Megre & 6 & 6 & 10 & 0 & 0 & 0 & 22 & 19 \\
\hline José Saramago & 127 & 236 & 238 & 10 & 3 & 37 & 651 & 4 \\
\hline Miguel Torga & 37 & 47 & 36 & 5 & 7 & 8 & 140 & 12 \\
\hline Pavão & 25 & 42 & 31 & 4 & 2 & 4 & 108 & 14 \\
\hline Raul Solnado & 41 & 78 & 112 & 6 & 1 & 18 & 256 & 8 \\
\hline Sá Carneiro & 172 & 345 & 245 & 30 & 14 & 43 & 849 & 2 \\
\hline Salazar & 73 & 277 & 195 & 12 & 0 & 9 & 566 & 6 \\
\hline Sophia & 26 & 35 & 25 & 5 & 3 & 5 & 99 & 15 \\
\hline Vítor Baptista & 5 & 5 & 6 & 0 & 0 & 0 & 16 & 20 \\
\hline Zeca Afonso & 35 & 66 & 53 & 7 & 7 & 13 & 181 & 10 \\
\hline
\end{tabular}


Comecemos, pois, pelos casos de Amália Rodrigues e Eusébio, duas das personalidades cuja morte teve maior cobertura nos jornais analisados. Amália e Eusébio podem ser enquadrados na categoria de heróis, na medida em que ambos conquistaram feitos grandiosos. Poder-lhes-íamos chamar mitos, até porque eles construíram a sua carreira em torno de dois setores, por vezes, considerados eles próprios "mitificadores" da realidade portuguesa - o fado e o futebol mas parece-nos que o mito precisa de várias décadas para se sustentar como tal e, além disso, mais do que modelos de vida, Amália e Eusébio começaram por ser embaixadores de Portugal, cada um na sua área. Este facto pode remeter para uma certa portugalidade, cujo caráter de misticismo se coaduna com a ideia de Roland Barthes (2001, p. 139), para quem o mito converte a história em natureza e a contingência em eternidade, infletindo a história e deformando-a. No entanto, defendemos que Amália e Eusébio representam de forma mais completa a definição de herói do que a definição de mito, uma vez que se destacaram pelos seus extraordinários feitos, reconhecidos de forma coletiva, fruto do seu génio e capacidade de superação de obstáculos.

No caso de Amália não podemos descurar o papel que teve no fado e na disseminação de uma parte da cultura portuguesa em todo o mundo, sendo certo que a opinião pública alia as suas origens humildes ao seu génio, ao seu esforço e trabalho. Amália vendeu mais de 30 milhões de cópias dos 170 discos editados em seu nome e da sua morte resultou o decreto de três dias de luto nacional. A dimensão da sua carreira e a importância do seu trajeto profissional estão espelhados no tratamento que os jornais analisados fizeram da morte de Amália Rodrigues. As três capas inteiras publicadas no dia após o seu falecimento são sinónimo do relevo do acontecimento, cuja dimensão foi suficiente para retirar todos os outros assuntos das primeiras páginas, à exceção do Correio da Manhã que adicionou uma pequena chamada no fundo da capa. Quanto ao conteúdo, todos os periódicos procuram recordar a vida de Amália Rodrigues, elencando os discos que editou, fazendo reportagens na rua onde a fadista vivia e abordando as diversas facetas da sua vida profissional (música, cinema, teatro) e algumas particularidades da sua vida pessoal. Somemos, pois, as 119 páginas em que foi referenciada, as 196 peças publicadas (das quais 38 dos géneros de opinião), as 206 imagens, os 13 destaques de capa e o total de oito efemérides assinaladas pelo conjunto dos jornais. Estas 567 unidades de análise identificadas denotam bem a relevância de Amália, sendo que, entre as peças publicadas, destacamos as 16 biografias e cinco cronologias publicadas, sinal da relevância do seu percurso profissional.

As conquistas e feitos no mundo do futebol parecem elevar também a figura de Eusébio ao estatuto de herói. À semelhança de Amália, o atleta tinha origens em nada coincidentes com o estatuto social que veio a alcançar e foi o seu talento e profissionalismo que o levaram a obter o reconhecimento público. Na sua carreira contam-se 1137 golos marcados, o recorde de títulos de campeão da I Divisão, estando ainda hoje entre os dez melhores goleadores de sempre e tendo recebido uma bola de ouro, duas botas de ouro e sete bolas de prata consecutivas. Quanto 


\section{Dentro desta}

\section{categoria de herói,}

ao tratamento dos jornais após a sua morte, apenas no Correio da Manhã o tema não mereceu uma capa inteira. O conteúdo dos dias que se seguiram assentou num significativo enfoque na carreira de Eusébio, recordando a história da sua vinda para Portugal e os momentos mais marcantes no futebol, bem como algumas particularidades da sua vida pessoal. Tendo em conta a tabela que construímos, o total de 1161 unidades de análise resulta de 202 páginas, onde figuraram 420 artigos (dos quais 79 dos géneros de opinião), 446 imagens, 17 destaques de capa, três efemérides assinaladas pelos três periódicos. Quanto ao enfoque biográfico, foram publicados 18 artigos classificados dentro deste género jornalístico e dez cronologias.

Estamos, assim, em condições de defender que a cobertura mediática da morte de Amália e Eusébio, se coaduna com o estatuto de herói, assente na ideia dos feitos grandiosos reconhecidos do ponto de vista coletivo e das habilidades especiais com impacto e reconhecimento na sociedade. Para esta conclusão contribuíram os dados quantitativos, sinónimo da extensão da cobertura, e os dados qualitativos, que parece-nos

que caberia

ainda o nome de

José Saramago,

conclusão, numa

primeira fase,

assente na sua

pródiga carreira

literária, cujo

expoente máximo

se traduz no

facto de ter sido

o único escritor

português a receber

o Prémio Nobel

da Literatura. denotam o enfoque na vida e obra de cada uma das personalidades. Acrescente-se, ainda, que o facto de ambos serem conhecidos apenas pelo primeiro nome indicia uma notoriedade que os eleva a um patamar superior nas categorias da fama.

Dentro desta categoria de herói, parece-nos que caberia ainda o nome de José Saramago, conclusão, numa primeira fase, assente na sua pródiga carreira literária, cujo expoente máximo se traduz no facto de ter sido o único escritor português a receber o Prémio Nobel da Literatura. À semelhança de Eusébio e Amália, também José Saramago alcançou a notoriedade na sua área, fruto do esforço e persistência. A soma das unidades de análise (65l) é superior à soma de Amália Rodrigues e o enfoque biográfico dos jornais também é significativo: 18 biografias e cinco cronologias. Ainda assim, e tendo como termo de comparação as figuras de Amália e Eusébio, a cobertura da morte de José Saramago remete-nos para um conceito que poderíamos definir como anti-herói, pois, sendo um herói naquilo que conquistou profissionalmente, não o foi completamente no reconhecimento 
público. As polémicas em que se viu envolvido, o seu ateísmo num país maioritariamente católico e o facto de ter optado por deixar Portugal para residir em Espanha tornaram-no numa personalidade menos consensual do que Eusébio e Amália. O próprio tratamento que os jornais deram à sua morte denota esta falta de consenso, patente nas polémicas que todos os periódicos destacaram, nomeadamente o saneamento dos jornalistas do Diário de Notícias e a decisão de viver em Lanzarote, encarada por muitos como um abandono do seu país. Ao mesmo tempo, os diários não deixaram de lhe dar um considerável destaque, sobretudo tendo em conta a distinção do Prémio Nobel.

O conceito de anti-herói presente na narratologia define esta figura como alguém com "debilidade ou indiferenciação de caráter, a ponto de assemelhar-se a muita gente" (Moisés, 2004, p. 28) e como sendo um protagonista em torno do qual se movem os restantes. No entanto, a sua configuração assenta na sua desqualificação, face aos defeitos e limitações que apresenta, culminando na ideia do homem sem qualidades
(Reis e Lopes, 1988, p. 192). Assim sendo, encontramo-nos perante uma definição que não pode enquadrar José Saramago, sobretudo devido aos feitos que alcançou no mundo da literatura e à relevância que assumiu dentro e fora do país. Visto que a envolvente mais problemática da sua vida pessoal e profissional não é consonante com as caraterísticas tradicionalmente atribuídas aos heróis, na medida em que não existe unanimidade no seu reconhecimento público, optámos por classificar José Saramago como semi-herói, no sentido em que possui muitas das caraterísticas identificadas na cobertura noticiosa de Amália e Eusébio, mas soma-se-lhe um fator de falta de unanimidade, que não deixa de ser o contrário do que representa o herói.

Olhemos agora para a categoria dos famosos, ou seja, personalidades que gozam de conhecimento público pelos seus atos, mas cuja atenção mediática não é necessariamente contínua. Neste campo começamos por integrar Vítor Batista, cuja soma na nossa tabela de destaques não vai além das 16 unidades de análise. A sua ação no mundo do futebol tornou-o conhecido, mas esse estatuto nunca esteve dependente da sua omnipresença nos meios de comunicação de massas, tal como denota o tratamento da sua morte, e essa seria uma caraterística fundamental para que o categorizássemos como uma celebridade. Poderíamos também inseri-lo nas categorias de estrela ou vedeta, mas para isso seria necessário que ele estivesse integrado num star-system, o que até poderia ser verdade enquanto foi jogador de futebol, mas já não era o caso quando se deu a sua morte.

Partindo destas mesmas premissas, também José Megre pode ser definido como famoso, tendo alcançado uma soma de 22 unidades de análise na tabela de destaques. A verdade é que o facto de Megre se ter destacado no automobilismo, cujo menor relevo desportivo nos media face ao futebol é notório, trouxe-lhe também menor destaque na mediatização da morte. Assim, a sua categorização como famoso assenta nas suas conquistas e contributos para o desporto automóvel, bem como no escasso tratamento que os jornais fizeram do seu falecimento. A relevância que José Megre assume na nossa análise deve-se ao facto de mostrar que as competências dos 
sujeitos não são por si suficientes para se imporem publicamente: o que fazem depende também da sua significância e reverberação na opinião pública e nos media.

No que diz respeito ao setor da política, e no caso de António de Spínola, acreditamos poder incluí-lo na categoria do famoso, sendo claro que não poderíamos colocar esta personalidade na categoria de estrela ou vedeta pelo facto de ele não se integrar num star-system. Na soma da tabela, a morte de Spínola representa 115 unidades de análise e o tratamento de que foi alvo nos jornais denota a sua relevância histórica, expresso no facto de lhe terem sido dedicadas cinco biografias e três cronologias. No entanto, a dimensão do tratamento foi claramente inferior em relação a outros casos, nomeadamente pelo facto de as suas efemérides não terem sido assinaladas, à exceção dos 20 anos decorridos sobre a sua morte, recordada muito brevemente numa coluna de efemérides do dia no Correio $d a$ Manhã.

Ainda no âmbito da política, não foi fácil atribuir um estatuto às personalidades de Oliveira Salazar, Álvaro
Cunhal e Sá Carneiro. Nenhum deles poderia ocupar o estatuto de celebridade, na medida em que a exposição destas personalidades aos meios de comunicação social deriva dos cargos que ocupam politicamente e as suas narrativas pessoais revelam uma autonomia relativamente ao discurso mediático. Também não são estrelas nem vedetas, face à ausência de um star-system, e os seus feitos não alcançam o estatuto de herói.

Quanto ao caso de Oliveira Salazar, a soma de 566 unidades de análise é um número significativo tendo em conta que o Correio da Manhã ainda não existia quando da sua morte. Parece-nos que o antigo Presidente do Conselho é uma das personalidades do nosso estudo que reúne as caraterísticas necessárias para ser considerado um mito. Do ponto de vista temporal, uma componente a nosso ver fundamental para que possamos falar de mitos, tivemos em conta que já passaram quase 50 anos sobre a sua morte. Concomitantemente, o tratamento que os jornais deram à cobertura da sua morte indicia, precisamente, a tentativa explícita de construção de um mito, tendo por referência um certo modelo de vida pessoal e enquanto figura de Estado. Os dois periódicos descreveram o político como sendo abnegado e humilde e ambos elencaram de forma exaustiva os contributos da sua ação pública. No caso particular do Diário de Notícias, Salazar é sobretudo venerado, fruto da posição do jornal face ao regime, pelo que nos parece que este posicionamento dá claros indícios de um processo conducente à sua mitificação, que esbarrou com os caminhos que a história assumiu. Em ambos os periódicos, Salazar foi apresentado como o homem que nunca tirou proveitos próprios do cargo que ocupou. O Diário de Notícias e o Jornal de Notícias contrapõem o poder que teve o Presidente do Conselho com a sua personalidade de homem humilde que foi a enterrar numa campa rasa na localidade onde nasceu. Um elemento que não podemos deixar passar em claro na análise deste discurso é o contexto de censura que, de alguma forma, misturou a narrativa oficial do Estado Novo com a narrativa mediática. Se, por um lado, podemos argumentar que os periódicos adotaram um discurso que visava contribuir para tornar Salazar num mito, por 
outro lado não podemos esquecer que esse discurso foi condicionado pela vigilância dos serviços de censura, no caso do Jornal de Notícias, e pelo papel propagandístico assumido pelo facto de se tratar do jornal do regime, no caso do Diário de Notícias. A comprovar o caráter construído do discurso da mitificação está o desaparecimento de Salazar das páginas dos jornais após o 25 de Abril de 1974: o ex-Presidente do Conselho não foi alvo de qualquer referência nos aniversários da sua morte que aconteceram já em democracia, o que em termos objetivos significa a eliminação do discurso em torno da construção do mito. Apesar desta circunstância, não podemos esquecer que a definição de mito diz que a tradição oral prolonga o estatuto no tempo. É precisamente com base nesta ideia que defendemos que a figura de Salazar se mitificou, na medida em que o discurso detrator da sua personalidade por parte daqueles que sofreram diretamente as consequências do regime, não conseguiu abafar o discurso apologético dos que admiram a sua personalidade. Independentemente da conotação do discurso, Salazar está tão presente
É precisamente com

base nesta ideia que

defendemos que a

figura de Salazar se

mitificou, na medida

em que o discurso

detrator da sua

personalidade por

parte daqueles que

sofreram diretamente

as consequências

do regime, não

conseguiu abafar o

discurso apologético

dos que admiram a

sua personalidade. no discurso da oralidade, como está ausente do discurso dos media. Um dos aspetos que pesou nesta discussão tem a ver com os traços da sua omnipresença no seio da sociedade portuguesa, facto que explica a sua eleição, em março de 2007, como "o maior português de sempre", no programa da RTP "Grandes Portugueses", onde obteve $41 \%$ dos votos dos participantes. Também a título de exemplo, podemos recordar algumas notícias publicadas no jornal regional Diário de Viseu. Em março de 2012 o periódico escreveu uma reportagem de duas páginas com o tema "Quanto vale e o que representa a marca Salazar", dando voz a defensores e detratores do ex-Presidente do Conselho a propósito da intenção do município em registar uma marca com o nome de Salazar. Nessa reportagem pode ler-se:

A humildade de Salazar é elogiada em Santa Comba Dão, onde todos dizem que "nem para ele soube roubar". Numa placa colocada à entrada da sua casa pode ler-se: "Aqui nasceu Dr. Oliveira Salazar, um senhor que governou e nada roubou". "Era igual a estes 
políticos, agora só não matam, mas roubam", atirou um santacombadense.

Em novembro de 2012 a marca foi chumbada pelo Instituto Nacional da Propriedade Industrial (INPI), porque poderia "encerrar um teor marcadamente político perante a generalidade do público e, dessa forma, ser suscetível de ferir a consciência coletiva da nossa sociedade dada a conotação negativa que tal sinal inflige no espírito do consumidor". Na notícia, o município repudia o chumbo, defende que o nome Salazar deve fazer parte de uma marca identificativa dos produtos de Santa Comba Dão e a população daquele concelho declara que os turistas que passam pela cidade perguntam pela casa de Salazar, pela campa, pela estátua, pelo museu e também pelo vinho, mesmo sem este estar a ser comercializado. Estes dois exemplos mostram que a presença de Salazar no discurso mediático é residual, mas, sobretudo, denotam a sua omnipresença no discurso do público, seja de forma negativa ou positiva. Dir-se-ia que à narrativa oficial de outrora que mitificou Salazar, contrapõe-se, atualmente, outra narrativa, procurando impor a sua desmitificação.

Também no que diz respeito a mitos, encontramos o caso de Álvaro Cunhal, cuja soma de unidades de análise é de 693. Este caso assume uma particularidade temporal, visto que não faleceu há tempo suficiente para podermos dizer que, do ponto de vista mediático, está consolidada a sua imagem como um mito. No entanto, no decorrer da nossa análise, confrontámo-nos com um discurso por parte dos jornais que atribuía a Álvaro Cunhal as caraterísticas de abnegação e a relevância, enquanto símbolo político, que também identificámos em Salazar, não obstante as profundas diferenças ideológicas existentes entre ambas as figuras. De facto, Álvaro Cunhal faleceu em 2005, tempo a nosso ver insuficiente para podermos afirmar estar perante um processo de mitificação da personagem. Parece-nos, porém, que podemos estar perante um mito em construção, conclusão sobretudo assente no significante destaque que teve o seu falecimento no discurso dos jornais. Quando da cobertura da sua morte, o Jornal de Notícias identificou Álvaro Cunhal, por cinco vezes, com a palavra mito, nomeadamente num título que refere como o "Mito mantém o rumo do partido", numa referência ao PCP, ou no texto de um editorial, que remata dizendo que "o mito de Álvaro Cunhal perdurará". Cunhal foi ainda descrito como "raro carismático", "filho adotivo do proletariado" e como "herói do movimento comunista", referências que ajudam a consolidar a figura como um mito em construção, tal como confirmamos quando das efemérides, face à importância que lhe foi dada pelo Diário de Notícias e Jornal de Notícias. A conotação de Cunhal como mito por parte dos jornais pode ser encarada do prisma dos atos perlocutórios de fala, no âmbito da teoria de John Austin. Segundo o autor (Austin, 1962, p. 101), o enunciado performativo, além da sua locução, ou seja, daquilo que diz, produz algo pelo facto de o dizer. Segundo o autor dizer qualquer coisa provocará alguns efeitos "sobre os sentimentos, os pensamentos, os atos da audiência, ou daquele que fala ou de outras pessoas ainda". Dizer que Álvaro Cunhal é um mito não tem necessariamente de corresponder a uma categorização definitiva da 
personalidade, mas a afirmação, ao mesmo tempo que exerce uma ação de locução perante os leitores, pode ser a expressão de uma tendência que o futuro elucidará. De facto, ao dizê-lo, o jornal está, de certo modo, a instituir esta categoria e o facto de ela vir ou não a ser aceite depende daquilo a que Austin chama de "condições de felicidade". No fundo, defendemos que os jornais abriram caminho para que Cunhal possa ser considerado como mito, ainda que não o possamos considerar como tal.

Mais uma vez, salvaguardadas as profundas diferenças ideológicas, a ideia de abnegação e de humildade da personalidade é a mesma que ajudou a construir o mito de Salazar e que encontra algum paralelo no discurso dos jornais após a morte do ex-líder do Partido Comunista Português. Consideramos, pois, que na mesma medida em que Salazar foi um mito construído pelos jornais ideologicamente orientados e mantido fruto de uma espécie de omnipresença da sua figura entre o povo português, Álvaro Cunhal é tido como um mito dentro das paredes partidárias e o discurso dos jornais após a sua morte pode ter servido para instituir essa ideia fora do campo político.

Ainda no campo da política e dos mitos, não podemos esquecer o caso de Sá Carneiro, que representa uma das somas mais elevadas da nossa tabela: 849 unidades de análise. De realçar que, além de Salazar e Amália, Sá Carneiro foi a única personalidade cuja morte foi noticiada com capa inteira nos três jornais analisados e foi também aquela com maior número de efemérides assinaladas. As circunstâncias da morte do ex-primeiro-ministro criaram uma aura em torno dele, na medida em que, desde 1980 até 2006, foram levadas a cabo uma série de investigações que visavam aferir sobre as causas da sua morte: acidente ou atentado. Após a prescrição do caso de forma inconclusiva, tiveram lugar novas comissões de inquérito parlamentares e a última, em 2013, refere a existência de provas que sustentam a tese de atentado, apesar de estas conclusões não serem taxativas. Ainda assim, o mistério em torno do seu acidente, bem como a excecionalidade das circunstâncias da morte (foi a primeira vez que um governante em exercício de funções morreu vítima de um atentado) parecem justificar um tratamento, por parte dos periódicos, que vai no sentido da construção do mito em torno de Sá Carneiro. Neste caso, quando falamos em mito falamos em modelo de vida para os outros, mas falamos também em misticismo. Após a morte de Sá Carneiro, os jornais descreveram-no, unanimemente, como um político de topo, carismático e bem preparado. Expoente máximo desta ideia de Sá Carneiro como modelo político está patente no Diário de Notícias, dez anos após a sua morte. A foto de capa do periódico tem o título "Influência de Sá Carneiro ainda é superior à de Soares". No interior encontramos a publicação dos resultados de uma sondagem que comparava a popularidade que Sá Carneiro ainda detinha, com a de Mário Soares, então Presidente da República. O mesmo jornal publica ainda uma sondagem sobre as suspeitas de crime, no que toca à sua morte.

No aniversário de dez anos passados sobre a sua morte, o Diário de Notícias escreve oito páginas sobre Sá Carneiro e se este exemplo denota a ideia de Sá Carneiro como modelo de homem político, nele encontram-se traços claros 
de um mistério originado em torno do acidente que vitimou o político. De facto, em todas as efemérides assinaladas, à exceção dos seis meses, é invocado o mistério em torno do acidente e/ou a falta de provas que permitam chegar a uma conclusão. A incógnita em torno do acidente está bem patente quando dos 20 anos passados da morte de Sá Carneiro. Nesta data o Jornal de Notícias chega mesmo a escrever que "aos heróis fazem-se homenagens, porque a morte os colocou acima das debilidades humanas. Francisco Sá Carneiro é um desses mitos que a morte prematura ajudou a construir".

Consideremos agora para as personalidades ligadas ao star-system, enquanto sistema alternativo povoado por estrelas e vedetas que alimenta uma determinada área de mercado, seja o cinema, o desporto, a música ou a televisão. No campo do desporto, e tendo já considerado Eusébio como um herói, restam-nos Pavão e Joaquim Agostinho, atletas que chegaram perto do topo nas suas modalidades. De facto, quer Joaquim Agostinho quer Fernando Pascoal das Neves ficaram conhecidos pelos seus feitos e, à data da sua morte, cada um deles estava entre os melhores nas respetivas modalidades desportivas, o ciclismo e o futebol, respetivamente. Estamos, pois, perante duas estrelas no que toca ao mundo desportivo.

Joaquim Agostinho soma 198 unidades de análise e a sua morte foi tratada com grande pesar pelos jornais. $\mathrm{O}$ estatuto de estrela que lhe atribuímos coaduna-se com as quatro biografias e uma cronologia publicadas pelos jornais, bem como com a cobertura das inúmeras homenagens que tiveram lugar nos dias após o falecimento de Joaquim Agostinho. O próprio discurso do jornal denota essa ideia de estrelato, com a contabilização da palavra "campeão" 40 vezes nos textos dos três jornais e maioritariamente no Diário de Notícias.

Na tabela de destaques Pavão soma 108 unidades de análise, sendo de realçar a ausência do Correio da Manhã, que não existia à data da sua morte. $\mathrm{O}$ facto de o ex-futebolista ter falecido tragicamente no auge da sua carreira suporta a sua categorização como estrela, a par com o tratamento dos dois periódicos, sobretudo do Jornal de Notícias, que deram não só destaque à sua morte trágica, mas também aos feitos alcançados na sua carreira.

Considerando agora as artes (música, representação e literatura) como um star-system, faremos a distinção entre as estrelas, figuras de maior repercussão pública e mais duradouras no tempo, e as vedetas, que se aproximam ao estatuto da primeira, embora com uma duração mais efémera. $\mathrm{Na}$ categoria de vedeta inserimos as personalidades de António Variações e Carlos Paião, dado que nenhum dos dois teve tempo de se tornar numa estrela, face ao seu desaparecimento precoce.

António Variações soma 48 unidades de análise na nossa tabela, número relativamente baixo, sobretudo tendo em conta a relevância que o cantor assume hoje em dia. O ruído causado pelo facto de ter falecido vítima de uma doença então desconhecida, a Sida, bem como a sua personalidade excêntrica, podem ter interferido na cobertura da sua morte. Tendo em conta que a categorização que aqui ensaiamos é baseada nos dados biográficos em correlação com a análise, e não esquecendo a importância de António Variações para a música 
portuguesa, ele insere-se na categoria de vedeta dada a idade com que faleceu e a menor amplitude da cobertura do seu falecimento nos jornais.

No caso de Carlos Paião, também ele faleceu ainda jovem e a cobertura da sua morte pode ter sido condicionada pela coincidência com o incêndio do Chiado. Na tabela de destaques o cantor soma 29 unidades de análise, um número baixo e coincidente com a pouca atenção que o acontecimento teve nos jornais estudados. Assim, e apesar de também Carlos Paião assumir hoje um lugar de destaque na música portuguesa, considerámos o intérprete como uma vedeta, dado o parco tratamento que a sua morte mereceu na época.

Sobre José Afonso, a tabela de destaques que construímos dá-nos uma soma de 181 unidades, sendo que parte deles surge no período das efemérides. Hoje em dia encontramos José Afonso como uma personalidade de relevância dentro do panorama musical nacional, mas não foi essa relevância que detetámos na análise dos onze dias após a sua morte. Ainda assim, o nosso estudo mostrou, no âmbito dos dez e vinte anos da morte de José Afonso, que a evocação da sua memória foi consensual, tornando-se claro que o cantautor foi recordado pela relevância da sua ação na música, bem como pelo contributo da sua música para a luta pela liberdade. Assim, a nosso ver, José Afonso assume caraterísticas de uma estrela, marcada pela durabilidade da sua posição no panorama mediático, ainda que a sua morte tenha sido tratada pelos jornais de uma forma que não se coaduna com esta posição. São as efemérides que denotam a construção da personalidade como uma estrela, que emerge à medida que $\mathrm{o}$ artista foi esbatendo a figura do homem político que também foi.

Entre as outras estrelas, cuja ação foi, então, mais duradoura dentro do star-system das artes, podemos enquadrar Miguel Torga e Sophia de Mello Breyner. Foram dois dos autores portugueses várias vezes indicados para o Prémio Nobel e que deixaram, através do seu legado literário, a necessária durabilidade que define o discurso mediático sobre as estrelas. Categorizar dois nomes maiores da literatura como estrelas pode parecer-nos um pouco desadequado, dado que a estrela está muitas vezes associada à ideia de mediatismo do seu star-system e a literatura não é o setor que mais se proporciona para este tipo de tratamento por parte dos media. Ainda assim, é inegável o papel de relevo que ambos assumem dentro da literatura.

Sophia de Mello Breyner soma 99 unidades de análise e a sua morte mereceu bastante atenção por parte dos jornais analisados, sendo de destacar o facto de os periódicos, sobretudo o Jornal de Notícias, terem dado um claro enfoque biográfico no tratamento do tema. No total, foram publicadas seis biografias nos jornais. As efemérides assinaladas reforçam a categorização de Sophia como estrela e a trasladação do corpo para o Mosteiro dos Jerónimos dez anos após a sua morte confirma esse mesmo estatuto.

Miguel Torga soma 140 unidades de análise e o pendor biográfico presente nos jornais também é assinalável (seis biografias publicadas), o que, a nosso ver, é um fator significante da relevância que a personalidade assumiu nos media. Ainda assim, não podemos deixar de notar a ausência da cobertura das exéquias, talvez pelo facto de o funeral se ter realizado em Vila Real e o velório no Instituto Português de 
Oncologia. Por sua vez, as efemérides assinaladas denotam a memória dos jornais e a importância do escritor, uma vez que a primeira década após a sua morte chegou a ser chamada de capa do Jornal de Notícias. Assente na forma relevante como os jornais trataram Miguel Torga após a sua morte e no âmbito das efemérides, e alicerçando aqui a relevância da sua ação no panorama literário, enquadrámos o escritor na categoria de estrela.

No caso de Beatriz Costa assomava uma dúvida: ela não morreu como uma estrela, mas foi uma estrela do teatro e do cinema. Ao contrário de Vítor Baptista, o legado de Beatriz Costa permaneceu intacto, apesar de ela se ter retirado do ativo 36 anos antes de morrer. Além disso, ela construiu a sua biografia pública no teatro de revista e no cinema, durante a primeira década do século XX, e esse contexto é próximo do star-system. A tabela de destaques resulta em 77 unidades e a análise que realizámos mostra que a morte de Beatriz Costa assumiu alguma relevância para os jornais, mas estes praticamente se limitaram a noticiar a sua morte e recordar a sua vida. O Jornal de Notícias, por
Ao contrário de

Vítor Baptista, o

legado de Beatriz

Costa permaneceu

intacto, apesar de

ela se ter retirado

do ativo 36 anos

antes de morrer. exemplo, nem sequer cobriu o funeral da atriz. Além disso, a inexistência de efemérides denota, por um lado, a falta de memória, e, por outro, nega o tal estatuto de estrela que Beatriz Costa teve em vida. Assim, optámos por considerar Beatriz Costa como uma vedeta, que não se conseguiu impor ao discurso dos media para além da sua vida.

Os casos de Raul Solnado e António Feio, ainda que podendo ser categorizados como estrelas, são os únicos que também partilham das caraterísticas das celebridades. $\mathrm{O}$ facto de terem trabalhado até à data da sua morte garantiu a sua longevidade no discurso mediático e social. Para além disso, a visibilidade que resulta do facto de trabalharem na televisão, deu-lhes acesso direto à categoria de celebridade. Não podemos esquecer, a este propósito, que as celebridades implicam uma atenção na narrativa pessoal da personalidade e tanto Raul Solnado como António Feio viram, recorrentemente, as suas vidas e as dos que lhes eram próximos serem alvo da atenção dos media.

No caso de Raul Solnado, a soma dos destaques é de 256 unidades de 
análise, sendo de realçar a presença da opinião (18 das 78 peças escritas), apesar da quase inexistência de efemérides. De facto, a sua popularidade pode ser aferida pelos vários textos de opinião publicados após a sua morte. Durante a cobertura da sua morte notámos um grande enfoque na sua carreira por parte dos jornais, com seis biografias publicadas, sinónimo de que alcançou um considerável estatuto mediático. Simultaneamente, registámos um interesse pela sua vida pessoal, até porque a filha, Alexandra Solnado, e a neta, Joana Solnado são figuras públicas e estiveram em destaque nas imagens da cobertura das exéquias.

No caso de António Feio falamos de um menor número de unidades de análise (161), uma componente biográfica similar, com a publicação de cinco biografias, e um interesse mais vincado pela sua narrativa pessoal. Este enfoque está patente no destaque dado à doença que vitimou o ator, aos seus relacionamentos amorosos e à relação com os filhos, bem como a factos paralelos e insignificantes para a cobertura jornalística, como a sua vida amorosa ou o seu gosto por carros de alta cilindrada.
Assim, concluímos que estas duas personalidades congregam caraterísticas de estrelas e, simultaneamente, de celebridades. No entanto, comparativamente com a cobertura dada a outras personalidades analisadas, decidimos incluir António Feio e Raul Solnado na categoria de celebridades, quer pelo número de destaques que somam, quer pela exposição mediática das suas áreas de atividade e, sobretudo, face ao tratamento que foi dado às suas mortes pelos jornais analisados, nomeadamente do ponto de vista do enfoque nas suas vidas pessoais.

Ainda na categoria das celebridades, incluímos Angélico Vieira, personalidade que somou 334 unidades de análise na nossa tabela, facto que representa a sétima maior cobertura jornalística, entre os restantes casos tratados. Olhando apenas para os seus dados biográficos, poder-se-ia argumentar que o cantor se encaixaria melhor na categoria de vedeta, mas a sua narrativa pessoal constantemente explorada pelos meios de comunicação social e a sua permanente exposição mediática definem-no como uma celebridade, algo que confirmámos aquando da análise. Também ele tinha uma profissão de exposição constante na televisão e, como já referimos, a relação de cinco anos que manteve com uma outra conhecida atriz fizeram dele capa de várias publicações, não tanto pela vida profissional, mas sim por razões da sua vida pessoal. $O$ destaque de aspetos irrelevantes para a cobertura da sua morte, como o facto de ter salvado um cão alguns dias antes de morrer, confirmam esta opção na categorização.

\section{Conclusão}

Ao analisarmos a morte das personalidades que escolhemos para serem alvo deste estudo, deparámo-nos, desde logo, com a inevitabilidade do enquadramento de cada uma delas em diferentes tipologias de atenção pública, de reconhecimento e grau de realizações profissionais, enformadas em categorias oriundas da distinção entre os diversos graus de notoriedade. Essa notoriedade ajudou a traduzir a maior relevância da morte de algumas personalidades em relação a outras, mas concluímos que existem outros fatores que ampliam, perturbam ou enviesam a cobertura da morte. 
A categorização que aqui ensaiámos pode suscitar a criação de uma metodologia para verificação das categorias propostas aplicada às personalidades públicas. Reiterando que a nossa proposta decorre dos dados encontrados durante a análise, e não sendo uma categorização estanque, este esforço poderá ser o ponto de partida para novos aprofundamentos, bem como para a exploração de outras categorias das figuras mediáticas e da sua construção narrativa.

\section{REFERÊNCIAS \\ BIBLIOGRÁFICAS}

AUSTIN, J. (1962). How to do things with words. Oxford: Clarendon Press.

BARTHES, R. (2001). Mitologias. Rio de Janeiro: Bertrand Brasil.

BOORSTIN, D. J. (2006). From hero to celebrity: the human pseudo event. In P. D.

Marshal (ed.), The celebrity culture reader (pp. 72-90). Nova Iorque: Routledge.

CAMPBELL, J. (1990). O poder do mito. São Paulo: Palas Atena.

CAMPBELL, J. (1994). O herói de mil faces. São Paulo: Cultrix/Pensamento.
CASHMORE, E. (2006). Celebrity / culture. Nova Iorque: Routledge.

COELHO, M. C. (2011). O dilema do fã: a experiência emocional da idolatria. In E. Cintra Torres, \& J. P. Zúquete (eds.), A vida como um filme: fama e celebridade no século XXI (pp. 198-216). Alfragide: Texto Editores.

GABLER, N. (2001). Toward a new definition of celebrity. Disponível em: www.learcenter.org/pdf/Gabler.pdf

GALTUNG, J.; RUGE, M. H. (1965). The structure of foreign news. In Journal of peace research, 2(1), 64-91.

HARTLEy, J. (2004). Comunicação, estudos culturais e media. Lisboa: Quimera.

MARSHALL, P. D. (2006). Intimately interwined in the most public way: celebrity and journalism. In P. D. Marshall (Ed.), The celebrity culture reader (pp. 315-323). Nova Iorque: Routledge.

MOISÉS, M. (2004). Dicionário de termos literários. São Paulo: Cultrix.

PARAFITA, A. (2012). Antropologia da comunicação - ritos, mitos e mitologias. Lisboa: Âncora Editora.

REIS, C. (2015). The special one. Fenomenologia do herói desportivo. In Mediapolis, 1, 31-53.
REIS, C.; LOPES, A. C. (1988). Dicionário de teoria da narrativa. São Paulo: Ática.

RIVIÈRE, C. (2011). Introdução à antropologia. Lisboa: Edições 70.

ROCKWELL, D., \& GILES, D. (2009). Being a celebrity: a phenomenology of fame. Journal of Phenomenological Psychology, 40, 178-210.

ROJEK, C. (2001). Celebrity. Londres: Reaktion Books lda.

SANTOS, R. (2011). Fãs e celebridades. In Comunicação \& cultura, 12, 11-20.

TORRES, E. C. (2011). Televisão: A celebridade em estado natural. In E. Cintra Torres,

\& J. P. Zúquete (eds.), A vida como um filme: fama e celebridade no século $X X I$ (pp.

81-104). Alfragide: Texto Editores.

TURNER, G. (2004). Understanding celebrity. Londres: Sage Publications. 